IRA-International Journal of Technology \& Engineering ISSN 2455-4480

Proceedings of the

International Conference on Science \& Engineering for Sustainable Development (2017) Pg. no.358-363

Published by: Institute of Research Advances https://research-advances.org/index.php/IRAJTE

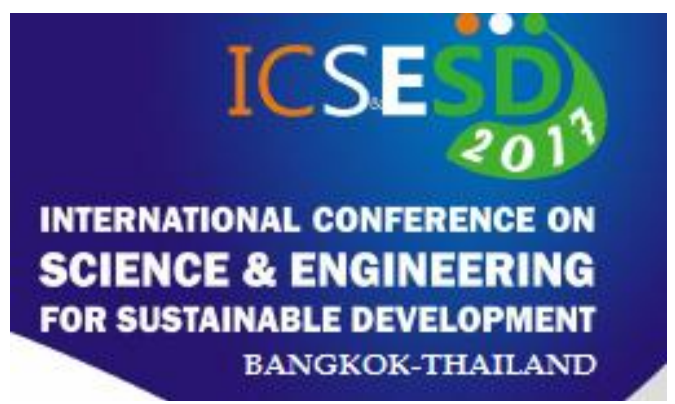

\title{
Extended of Durability Molds for Production Tires with New Types of Coatings
}

\author{
Irena Lysoňková ${ }^{1}, J^{\prime}$ Novotný ${ }^{* 2}$, Jaromír Cais ${ }^{3}, \check{S ̆ t e f a n ~ M i c h n a ~}^{\mathbf{4}}$ \\ 1,2,3,4 Faculty of Production Technology and Management, J. E. Purkyne University in \\ Usti nad Labem. Pasteurova 3334/7, 40001 Usti nad Labem. Czech Republic. \\ E-mail: lysonkova@fvtm.ujep.cz, novotny@fvtm.ujep.cz, cais@fvtm.ujep.cz, \\ michna@fvtm.ujep.cz
}

Type of Review: Originality Check \& Peer Review under the responsibility of the Scientific Committee of the Conference and The Institution of Engineers (India).

DOI: http://dx.doi.org/10.21013/jte.ICSESD201734

How to cite this paper:

Lysoňková, I., Novotný, J., Cais, J., Michna, S. (2017). Extended of Durability Molds for Production Tires with New Types of Coatings. Proceedings of the International Conference on Science \& Engineering for Sustainable Development (2017), 358-363. doi: http://dx.doi.org/10.21013/ite.ICSESD201734

(C) International Conference on Science \& Engineering for Sustainable Development \& The Institution of Engineers (India).

\section{(cc) BY-No}

This work is licensed under a Creative Commons Attribution-Non Commercial 4.0 International License subject to proper citation to the publication source of the work.

Disclaimer: The conference papers as published by the Institute of Research Advances (IRA) are the views and opinions of their respective authors and are not the views or opinions of the IRA. The IRA disclaims of any harm or loss caused due to the published content to any party. 


ABSTRACT
In this article is described the creation nanocomposite coating. It is PTFE coating with the addition of
particles based on titanium dioxide on the size „nano “. Working with nanoparticles is demanding not
only of safety, preparing particles of a size „,nano" and their subsequent uniform deployment in
coating (partiles of this size tend to influence the electrostatic forces of aggregation). In the first part
of the paper it is thus described a suitable nanoparticles percentages concentration relative to the
total content solution. Further described herein is a coating technology, Further disclosed herein is
coating technology since, without scattering particles during coating are prone to stick to the bottom
of the coating vessel. To evaluate the appropriate distribution of particles of mountings was used a
scanning electron microscope and EDS analysis.

Keywords: nanoparticles, nanocomposite coating, titanium dioxide, PTFE coating

\section{Introduction}

This article deals with the problems of the creation of nanocomposite coatings. Application of this coating is used for molds producing vulcanization of rubber. Specifically used for the production of tires in the automotive industry. The mold segments is in fig. 1.

The substrate for coating is an alloy of type $\mathrm{Al}-\mathrm{Si}$. A nanocomposite coating is composed of PTFE coating and particles based on titanium dioxide.

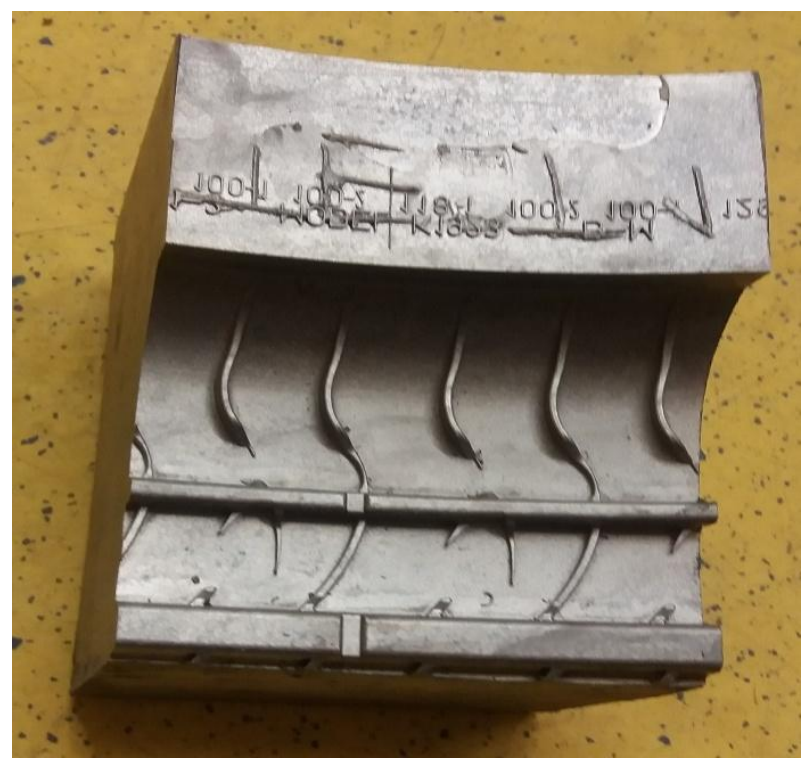

Fig. 1 Segment of mold

\section{Coated substrate}

To the create the experimental samples of coating were used the mold slots. It is on alloy of type $\mathrm{Al}-$ $\mathrm{Si}$., which is standardlly used to prodce these segments. The whole mold is composed of 8-36 segments, which are joined in unit to form the shape of the final product. Namely it is AlSi10CuNiMn alloy whose composition is verified by an optical emission spectrometer Q4 TASMAN in tab. 1 [1]

Production of the segments is performed by successive low-pressure casting alloy in casting furnaces. Hereis the melt maintained at a constant temperature, so there is emphasis on its properties constant 
over time. The tires are produced by vulcanization at $150^{\circ} \mathrm{C}$ to $170^{\circ} \mathrm{C}$ (depending on the added additives can vulcanization even at temperatures up to $200^{\circ} \mathrm{C}$ ). Due to the work at this temperature is required stability properties at normal and elevated temperatures. [1]

Tab. 1 Suggested chemical composition of AlSi10CuNiMn

\begin{tabular}{|l|c|c|c|c|c|c|}
\hline Element & $\mathrm{Si}$ & $\mathrm{Cu}$ & $\mathrm{Ni}$ & $\mathrm{Mn}$ & $\mathrm{Mg}$ & $\mathrm{Sr}$ \\
\hline Content [\%] & $8,5-10$ & $0,6-1,2$ & $0,6-1,0$ & $0,3-0,7$ & $0,3-0,5$ & $0,03-0,005$ \\
\hline
\end{tabular}

\section{PTFE coating}

Vulcanization of rubber materials is possible even without any coating. During production of mold maintenance is needed after 2500 to 2700 cycles. Maintenance is performed with cleaning in the form of individual segments manually using steel or grinding brushes, or by means of dry ice followed by mechanical cleaning. Due to time leads to financial losses that should be degraded form extend the time between maintenance. During the maintenance is also to considerable wear mold and due to cost hundreds of thousands to millions of crowns is suitable modification technology to extend the maintenance time. [2]

One of the possible extension of the time the application is PTFE coating. Due to the necessary dimensional accuracy is suitable for the coating, which is secreted by a very thin layer which thus resulting product barely interacts. Coating process is shown in fig. 2 . Since in this application was delayed cycle of 200 to $400 \%$, also occurs considerable financial savings. [2]

Because of the emphasis on further cost savings, it is advisable to improve the coating. In this case the addition of the particles based on titanium dioxide. The application of the powder coating is problematic in terms of capturing particles and uniform distribution of particles in the coating.

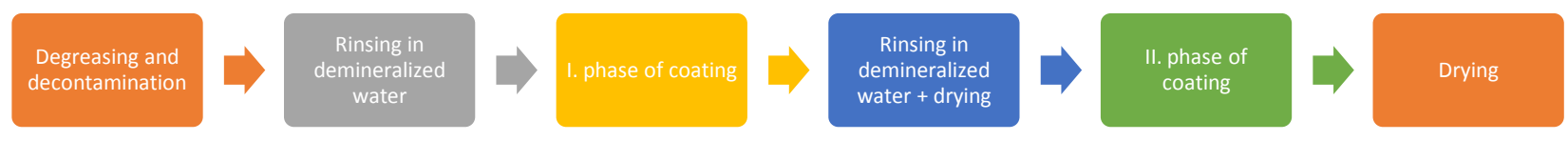

Fig. 2 Scheme applicatin of PTFE coating

\section{Formation of nanocomposite coating}

The addition of nanoparticles was carried out in II. phase coating. However, the first solution of the problem, the quantity of applied powder. In the first phase they were used in concentrations of $2 \%$, $5 \%$ and $9 \%$. Results of evaluation on the scanning electron microscope were satisfying, however, during a coating operation, there was considerable adhesion of large amount of particulate on the bottom of the coating vessel (see Fig. 3) even when an attempt dispersion and mixing glass stick. 


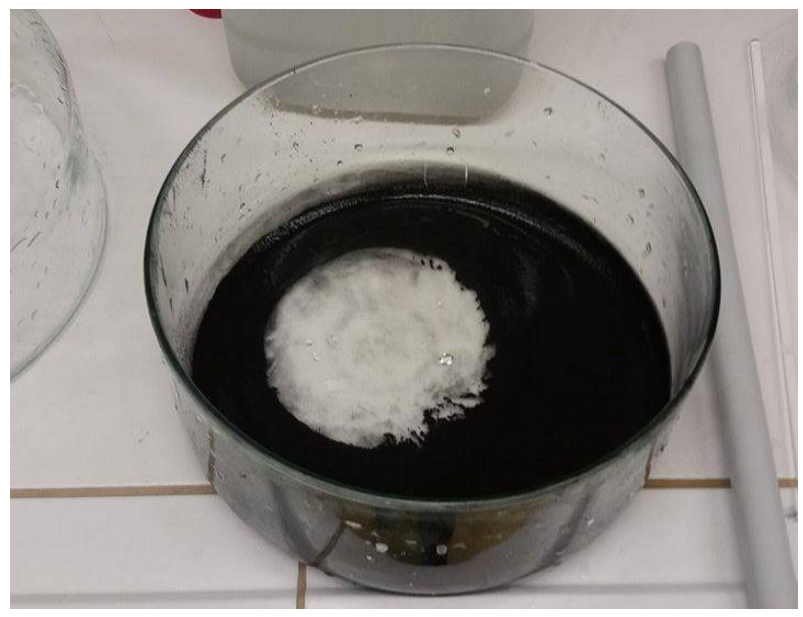

Fig. 3 Fixing excessive amount of nanoparticle based on titanium dioxide

In the second stage coating was used a magnetic stirrer, which was completely disperse the particles in a coating solution, all due to the large amount of particles became the samples not rate. The layer in this case was in the order of millimeters, see fig. 4.

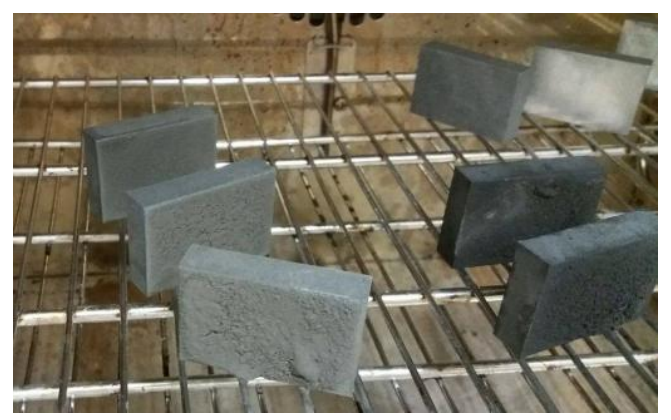

Fig. 4 Attachment of an excessive amount of coating

Due to this extreme amount was allowed to use the same technology of electromagnetic stirrers, but with concentrations of $0.5 \%, 0.05 \%, 0.01 \%, 0.005 \%$ and $0.001 \%$. To verify the suitable concentrations was used a scanning electron microscope TESCAN Vega 3 EDS analyzer equipped with a Bruker X-FLASH. As the most suitable concentration revealed $0.01 \%$. At lower concentrations were detected significantly smaller amount of particles, and at higher concentrations caught noticeable to the naked eye layer.

Images with uniform capture and identification are listed below. fig. 5 is a place where the surface analysis was performed using a scanning electron microscope. Fig. 6 shows the result of analysis where are the individual elements contained therein paeks. The weight and percent concentration of the analysis are shown in Tab. 2. From the analysis it can be determined that aluminum, silicon, magnesium is present in the substrate. Oxygen and fluorine are contained in PTFE coating. Titan is part of the additives to improve coating. 


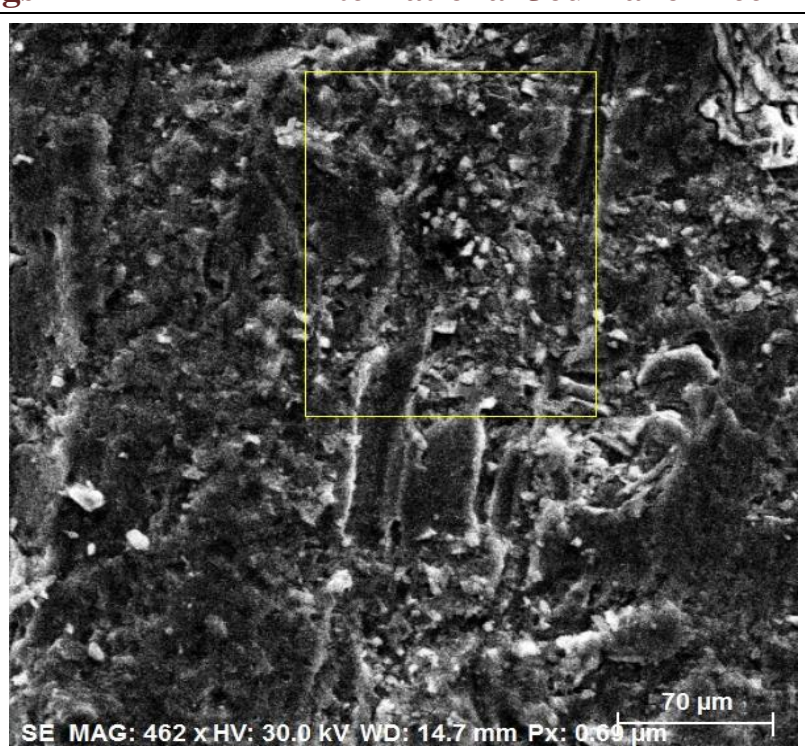

Fig. 5 Surface analysis of nanocoating

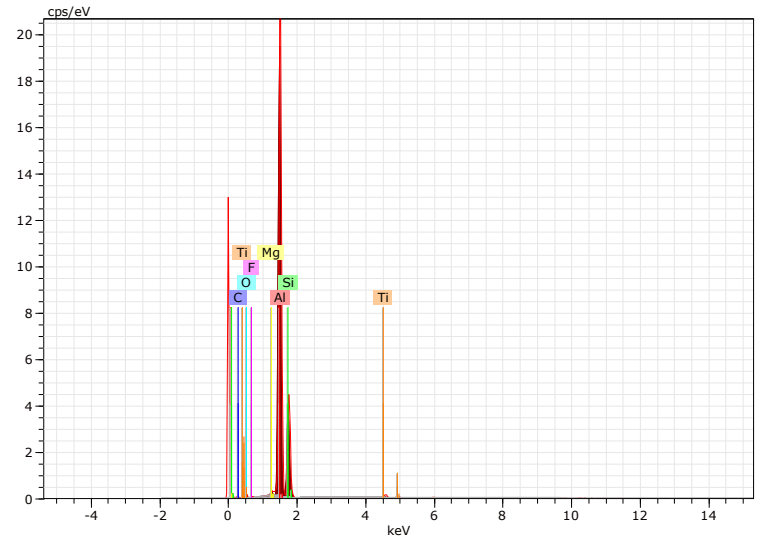

Fig. 6 Content of individual elements

Tab. 2 The weight and percent concentration of individual elements

\begin{tabular}{|c|c|c|c|c|}
\hline Element & Series & $\begin{array}{l}\text { unn. C r } \\
\text { [wt.\%] }\end{array}$ & $\begin{array}{l}\text { lorm. C } \\
\text { [wt.\%] [ }\end{array}$ & $\begin{array}{l}\text { Atom. C } \\
\text { at.\%] }\end{array}$ \\
\hline Aluminium & K-series & 56.15 & 53.28 & 44.66 \\
\hline Silicon & K-series & 26.66 & 25.30 & 20.37 \\
\hline Carbon & K-series & 13.09 & 12.42 & 23.38 \\
\hline Oxygen & K-series & 6.69 & 6.35 & 8.97 \\
\hline Fluorine & K-series & 1.63 & 1.55 & 1.84 \\
\hline Magnesium & K-series & 0.59 & 0.56 & 0.52 \\
\hline Titanium & K-series & 0.57 & 0.54 & 0.26 \\
\hline
\end{tabular}

During subsequent EDS analysis was confirmed uniform distribution of titanium in coating, see fig. 7. 


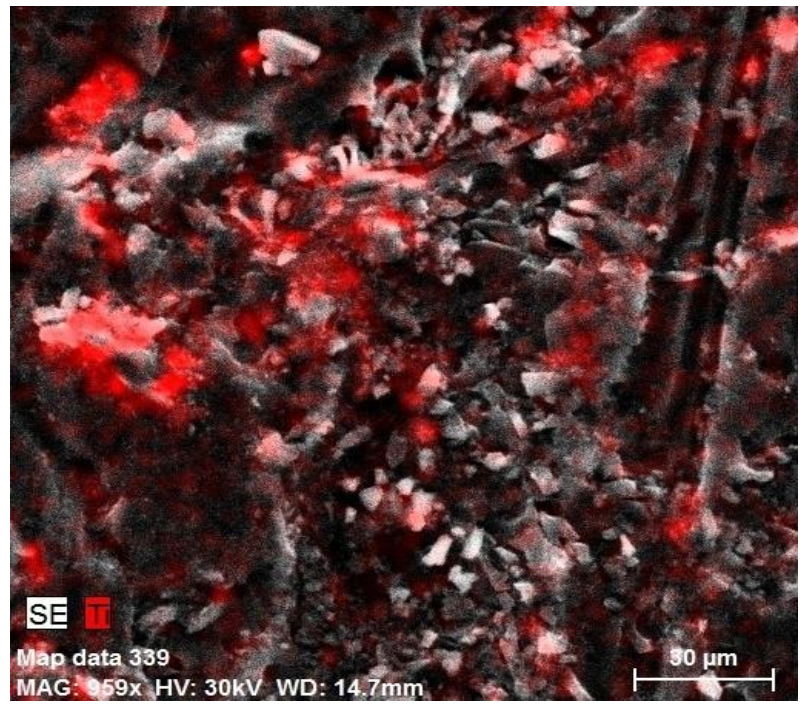

Fig. 7 Confirmation of uniform distribution by EDX analysis

\section{Conclusion}

During the experiment a coating was formed nanocomposite, which was confirmed by means of a scanning electron microscope and EDS analysis. This coating was made with a concentration of $0.01 \%$ of the particles of the titanium in the applied PTFE coating. This concentration was designated as the most suitable, due to the capture of too much or insufficient quantity of layers of particles. This coating is created to lifetime of prolongation molds for vulcanisation of rubber materials used in the automotive industry.

\section{Acknowledgement}

This article was created due to the project nr. 4820215001001 „SGS“ under the specific university research on FVTM JEPU.

\section{References}

[1] MICHNA, Š., CAIS, J.: CZ/28.07.15/CZA 20150521 Aluminium alloy in particular for the production of mould segment castings for forming types and the method of heat treatment of mould segment castings

[2] Užitný vzor: 13420/13:43885462 Zavedení technologie chemického povlakování Al forem za vzniku ochranných nanovrstev

[3] MICHNA, Š., CAIS, J.: CZ/28.07.15/CZA 20150521 Aluminum alloy in particular for the production of mould segment for forming typesand the method of heat treatment of mould segment casting

[4] SVOBODOVÁ, J., KUŚMIERCZAK, S.: New trends in surface pre-treatment. Toyotarity. Value Engineering of Production Processes. Borkowski, S., Stasiak-Betlejewska, R. Fakulty of Logistics, University of Maribor: AWR Edytor, 2012. ISBN 978-961-6562-60-7 